\title{
LARGE-SCALE SUBSIDENCE GEOHAZARD MONITORING WITH SENTINEL-1 SAR INTERFEROMETRY IN CENTRAL LISHUI (CHINA)
}

\author{
T. Qu ${ }^{1}$, Z. Su ${ }^{2, *}$, H. Yang ${ }^{3}$, X. Shi $^{4}$, W. Shao ${ }^{3}$ \\ ${ }^{1}$ College of Engineering, Peking University, Beijing 100871, China - tengteng.qu@pku.edu.cn \\ ${ }^{2}$ Institute of Mountain Hazards and Environment, CAS, Chengdu 610041, China - szmiyqq@imde.ac.cn \\ ${ }^{3}$ State Grid Zhejiang Electric Power Corporation, Hangzhou 310007, China - (yang hongzhen, shao weiping)@zj.sgcc.com.cn \\ ${ }^{4}$ School of Geography and Information Engineering, China University of Geosciences (Wuhan), Wuhan 430078, China - \\ shixg@cug.edu.cn
}

TS_DisasterManagement

KEY WORDS: InSAR, Sentinel-1, Large-scale Subsidence, Geohazard Monitoring, Urban Constructions.

\begin{abstract}
:
Ground subsidence has become a serious problem along with the rapid urban expansions. Compared with traditional point-based ground survey techniques (GPS, levelling measurement and in-situ sensors), SAR Interferometry are quite appreciated for large-scale subsidence monitoring with long term and high accuracy. In this study, we focused on large-scale subsidence geohazard monitoring of central Lishui (China) and extracted subsidence velocity map of Liandu District. 57 Sentinle-1 SAR images from April 2019 to September 2020 are analysed with SBAS-InSAR technique. The overall subsidence of Liandu is significantly correlated with the distributions of construction engineering sites with displacement velocity of approximately $30-60 \mathrm{~mm} / \mathrm{yr}$. Various types of urban ground subsidence could be identified, including the overall settlement of large construction site, the slope deformation of construction excavation, significant settlement of refuse landfill and mountain crossing tunnel, and small deformation of highvoltage towers in mountainous areas. Our results indicated that the rapid urban developments are the dominant impact factors of subsidence in Lishui, China.
\end{abstract}

\section{INTRODUCTION}

With the rapid development of urbanization, ground subsidence has gradually become one of the main geological disasters in urban areas of China, which has a serious impact on urban development, environment, construction, transportation, life and other aspects (Wu et al., 2016; Zhou et al., 2016). It has the characteristics of time lag, high monitoring difficulty, wide range of influence, long-term and slow deformation process. According to the Chinese national plan for the prevention and control of ground deformation from 2011 to 2020, since the ground deformation was first discovered in Shanghai in 1921 (Shi et al., 2008), more than 90 cities and regions in China have experienced ground deformation to varying degrees, the most prominent of which are the Yangtze River Delta, the Northeast China Plain and the Fenwei Basin.

The harm caused by ground deformation in cities mainly includes the decline of flood control and drainage engineering efficiency, the distortion and fracture of linear structures such as pipelines, the threat to the safety of rail transit, the subsidence of building foundation, the inaccuracy of ground benchmark, and even the ground fissure and ground collapse. For this type of deformation monitoring, it needs not only to meet the basic requirements of large-scale regional monitoring, but also to have enough accuracy and fast cycle to accurately and timely find the key areas that may have disasters. With precise levelling and GPS technology, accurate settlement data of several fixed positions could be achieved and the results could remain high reliabilities (Hinkel et al., 2001; Wu et al., 2010; Zorigt et al., 2016). However, levelling and GPS survey are all point-based with low point density, high observation cost and long repeated observation period. Especially, the observation results are not synchronous, which greatly limits the understanding of the development trend of regional ground subsidence. Moreover, in order to carry out large-scale regional ground subsidence observation, a large-scale monitoring network must be set up, which will inevitably lead to high construction cost of high-density monitoring points. Therefore, the regular manual ground survey method cannot meet the monitoring requirements of large interval, high precision and long-term observation for large-scale regions.

In recent years, SAR Interferometry (InSAR) are more and more appreciated with its wide coverage and high precision displacement monitoring capability (Bürgmann et al., 2000). Moreover, as there is no need for the layout and maintenance cost of the observation network, it is particularly suitable for the ground subsidence monitoring with large area and long term. The phase information recorded by complex SAR images could be used to measure subtle displacements with precision of a fraction of the wavelength. During the last decade, a set of time series InSAR techniques (e.g. the Persistent Scatterers InSAR (PSI) (Ferretti et al., 2001), the Small Baseline Subset method (SBAS) (Berardino et al., 2002), the Coherent Point Target (CPT) (Mora et al., 2003), and Interferometric Point Target Analysis (IPTA) (Werner et al., 2003), the SqueeSAR ${ }^{\mathrm{TM}}$ (Ferretti et al., 2011) and Temporal Coherent Point (TCP) (Zhang et al., 2012), and Coherent Scatterers InSAR (Dong et al., 2018)) have been proposed which could overcome the challenges from temporal and geometric decorrelations, the DEM uncertainties and atmospheric turbulence effect, hence are able to achieve millimetre accuracy especially in the urban area.

* Corresponding author 
Moreover, the new generation of SAR sensors including Sentinel-1, ALOS2 PALSAR2, TerraSAR-X, COSMO-Skymed which operate in orbit with short revisit cycles enable the widearea monitoring of ground displacement at high precisions nowadays (Gee et al., 2019).

In this study, we focused on large-scale subsidence geohazard monitoring of Lishui (China) and extracted subsidence velocity map of Liandu District in central Lishui covering more than 1,500 square kilometers during 2019-2020 with Sentinel-1 InSAR technique. The overall subsidence of Liandu is significantly correlated with the distributions of construction engineering sites, which also shows the continuous urban expansions in this developing city. Subsidence centres in Fuling and Huangfan Sub District were identified with displacement velocity of approximately $30-60 \mathrm{~mm} / \mathrm{yr}$. Our results indicated that the rapid urban developments are the dominant impact factors of subsidence in Lishui, China.

\section{STUDY AREA AND METHODOLOGY}

\subsection{Study Area}

Lishui City is located in the southwest of Zhejiang Province. It locates in the southeast Zhejiang fold belt, and the southwest section of Lishui-Ningbo uplift. The Lishui-Yuyao deep fault zone passes through the city, hence the terrain conditions are complex with strong rock weathering and fragile geological environment. It is recognized as the city with most serious geological disasters in Zhejiang Province. Especially in the last decade, Lishui has experienced great urban expansions with increased subsidence problems.

\subsection{Methodology}

In this study, 57 Sentinle-1 SAR images from April 2019 to September 2020 covering Liandu district of central Lishui are analysed with SBAS-InSAR technique. The ALOS World 3D 30m (AW3D30) DSM release by the Japan Aerospace Exploration Agency (JAXA) are used during co-registration, differential interferogram generation and geocoding processes. Because of short orbital cubes of Sentinel-1, the perpendicular baselines of Sentinel-1 interferometric pairs are short enough to guarantee the coherence qualities (Fig. 1).

Specifically, Liandu district has undulating terrains and abundant water vapor which results in severe problems of atmospheric disturbance in the SBAS-InSAR processing. Therefore, a time-series InSAR processing chain which integrates the atmospheric phase estimation was applied ( $\mathrm{Li}$ et al. 2009), to accurately separate the atmospheric disturbance and improve the reliability of time series displacement results.

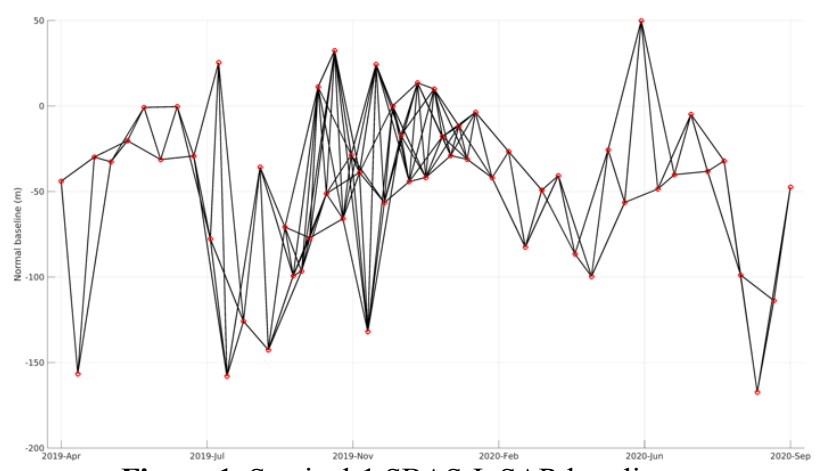

Figure 1. Sentinel-1 SBAS-InSAR baselines.

\section{RESULTS AND DISCUSSIONS}

\subsection{Mean Subsidence Velocity Map}

Fig. 2 shows the subsidence velocity map of Liandu District of central Lishui derived from Sentinel-1 SAR data during 2019 2020. Several subsidence centres in Huangfan and Fuling could be identified with the maximum subsidence velocity reaching over $50 \mathrm{~mm} / \mathrm{yr}$. Multiple types of urban ground subsidence could be identified, for example, the overall settlement of large construction site, the slope deformation of construction excavation, significant settlement of refuse landfill and mountain crossing tunnel.

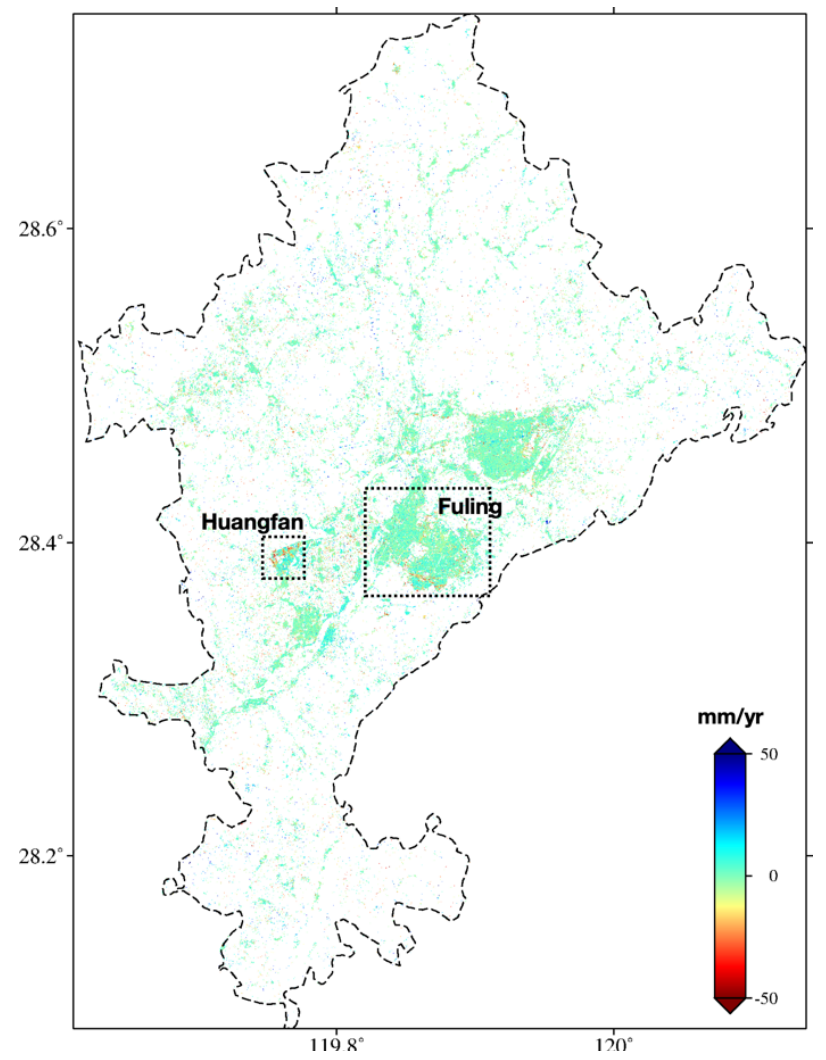

Figure 2. Subsidence velocity of Lian District, Central Lishui during 2019-2020.

\subsection{Significant Subsidence Sites}

The subsidence velocity of Fuling Sub District was given in Fig. 3. The displacements are mainly distributed along Fuling Road and several large construction sites, while the most serious displacement reached over $50 \mathrm{~mm} / \mathrm{yr}$. While FL1 and FL4 demonstrated significant overall subsidence around the construction project, FL2 and FL3 showed obvious slope deformation of construction excavations. 


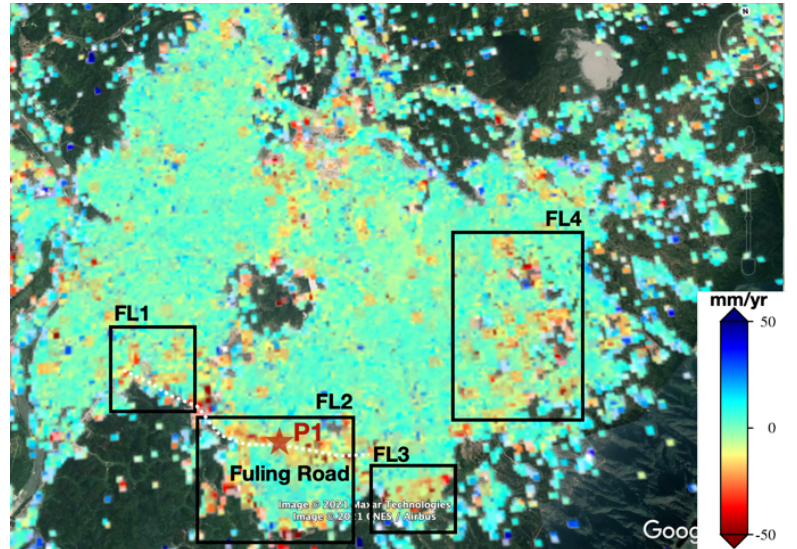

Figure 3. Subsidence velocity of Fuling Sub District during 2019 - 2020. The rectangles represent the corresponding locations in Figure 4 and 5. The white dash line represents Fuling Road.

Fig. 4 shows the Google Earth ${ }^{\mathrm{TM}}$ images of FL1 acquired at Sep. 2018 and Dec. 2019. We could see that a lot of urban constructions occurred in the surrounding area of FL1, especially along with the newly built of Fuling Road. As a result, the recent construction activities together with the artificial loading caused subsidence in these regions.
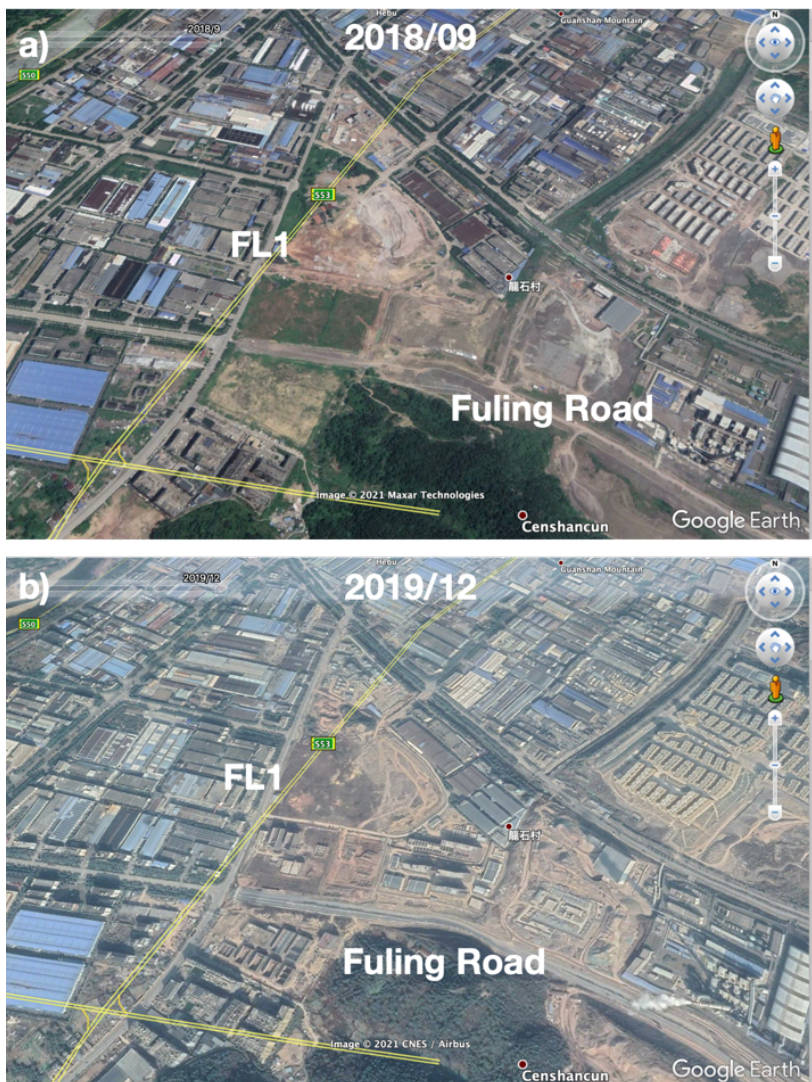

Figure 4. Google Earth ${ }^{\mathrm{TM}}$ images of FL1 acquired at Sep. 2018 and Dec. 2019.

The time-series displacement of P1 on Fuling Road in Fig. 3 is given in Fig. 5. The accumulative displacements of P1 could exceed more than $40 \mathrm{~mm}$ during the monitoring period. The subsidence trends are almost linear which closely correlated with the construction activities on Fuling Road.

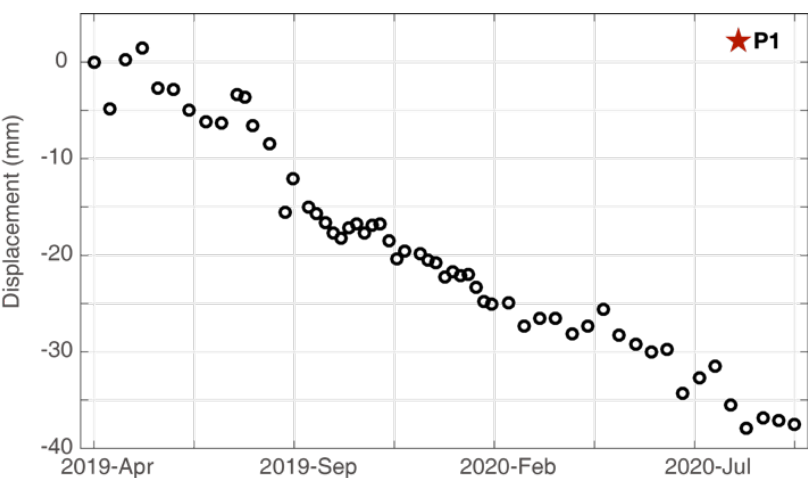

Figure 5. Time-series displacement of $\mathrm{P} 1$ on Fuling Road.

Similar urban construction induced subsidence could also been seen in FL4 from Fig. 3, while the Google Earth ${ }^{\mathrm{TM}}$ images of this region acquired at Sep. 2018 and Dec. 2019 is given in Fig. 6. Besides of a newly built road in the south of FL4, almost all areas have carried out large-scale construction projects in FL4. Where construction sites are concentrated, the settlement cannot be underestimated in urban areas.
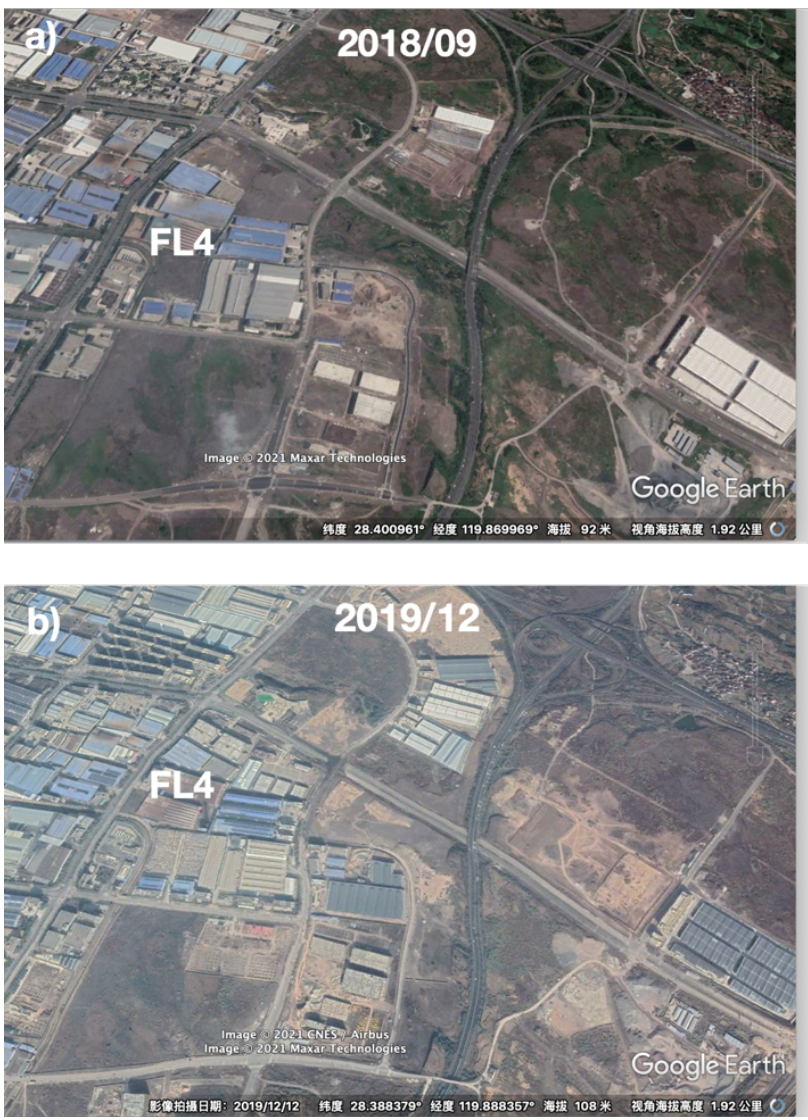

Figure 6. Google Earth ${ }^{\mathrm{TM}}$ images of FL4 acquired at Sep. 2018 and Dec. 2019.

Fig. 7 shows the Google Earth ${ }^{\mathrm{TM}}$ images of FL2 and FL3, 2 large construction sites surrounding with significant deformed construction slopes marked in white circles. Slope cutting and excavations in these construction engineering induced serious subsidence with deformation velocity over $60 \mathrm{~mm} / \mathrm{yr}$. The accumulative displacements of P2 on the excavation slope of FL3 are also given in Fig. 7. Due to the continuous excavation 
and backfilling of earthwork on this construction site, the settlement trend of P2 in 2019 is basically stable with fluctuation to a certain extent. However, due to the destroyed stability of the slope, P2 showed an obvious trend of continuous settlement during the rainy season of 2020. From this case, which cannot be ignored is that earth excavation is quite easy to cause serious slope disturbance and even local collapse, which needs to be monitored in long term and high accuracy.
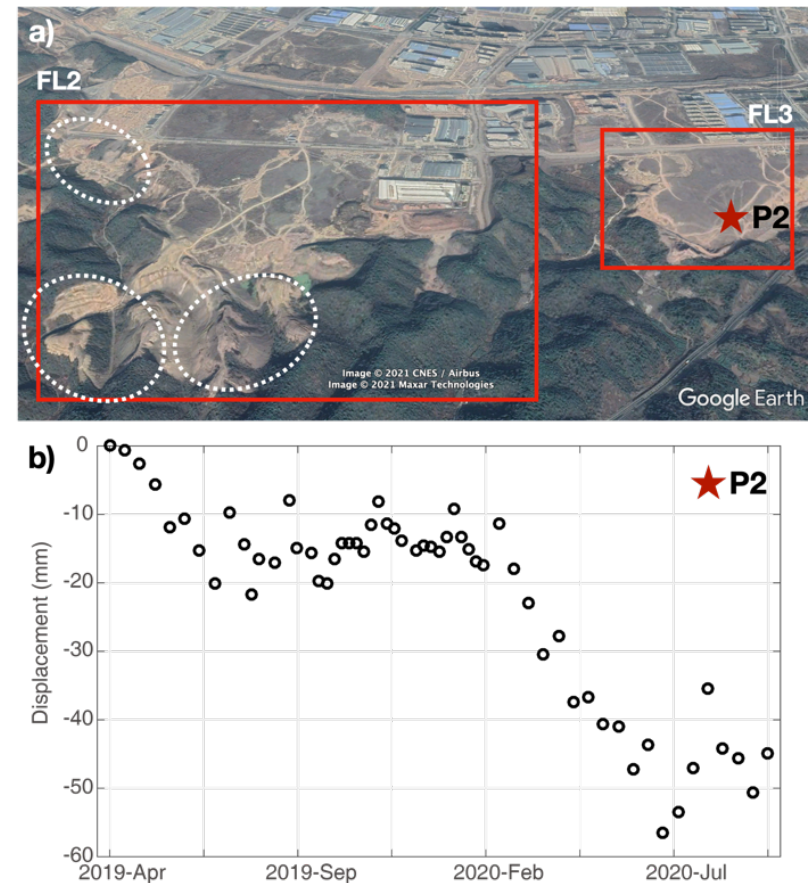

Figure 7. (a) Google Earth ${ }^{\mathrm{TM}}$ images of FL2 and FL3. The white circles mark the deformed construction slopes. (b) Timeseries displacement of $\mathrm{P} 2$ on the excavation slope.

Serious subsidence of a local refuse landfill site was also identified in our study as shown in Fig. 8. The settlement of sanitary landfill especially the long-term deformation is greatly influenced by the municipal solid waste. The large settlement of landfill site which can easily lead to the destruction of the buried pipeline system, is easy to produce adverse effects in the future. P3 represents the most serious deformed point in the landfill, whose accumulative displacements showed to exceed more than $80 \mathrm{~mm}$ in a year and a half. Moreover, the deformation trend of $\mathrm{P} 3$ showed almost linear with a significant settlement regularity, which could also be used to infer the degradation process and stabilization process of landfill site.
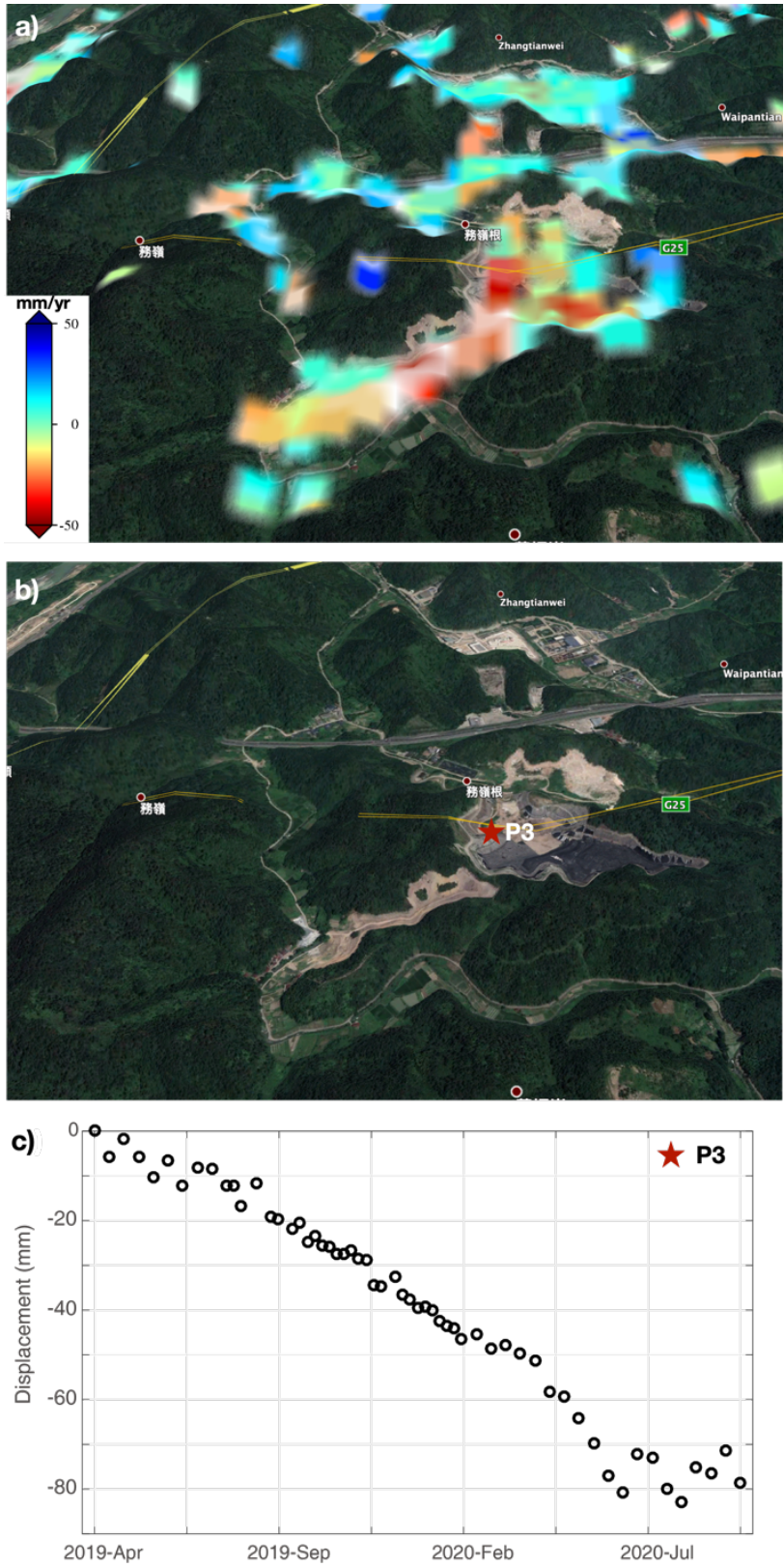

Figure 8. (a) Subsidence velocities of a local refuse landfill site. (b) is the corresponding Google Earth ${ }^{\mathrm{TM}}$ image of (a). (c) Timeseries displacement of $\mathrm{P} 3$ in the landfill.

The significant deformation of a mountain crossing tunnel was shown in Fig. 9. Displacement time series of P4 in the tunnel entrance could be retrieved and analyzed. Although the accumulative deformation of $\mathrm{P} 4$ is not quite serious, its deformation trend showed obvious correlation with the rainy season settlement in both 2019 and 2020. Affected by the dam water level and heavy rainfall in summer, the deformation of $\mathrm{P} 4$ also has significant fluctuations. 

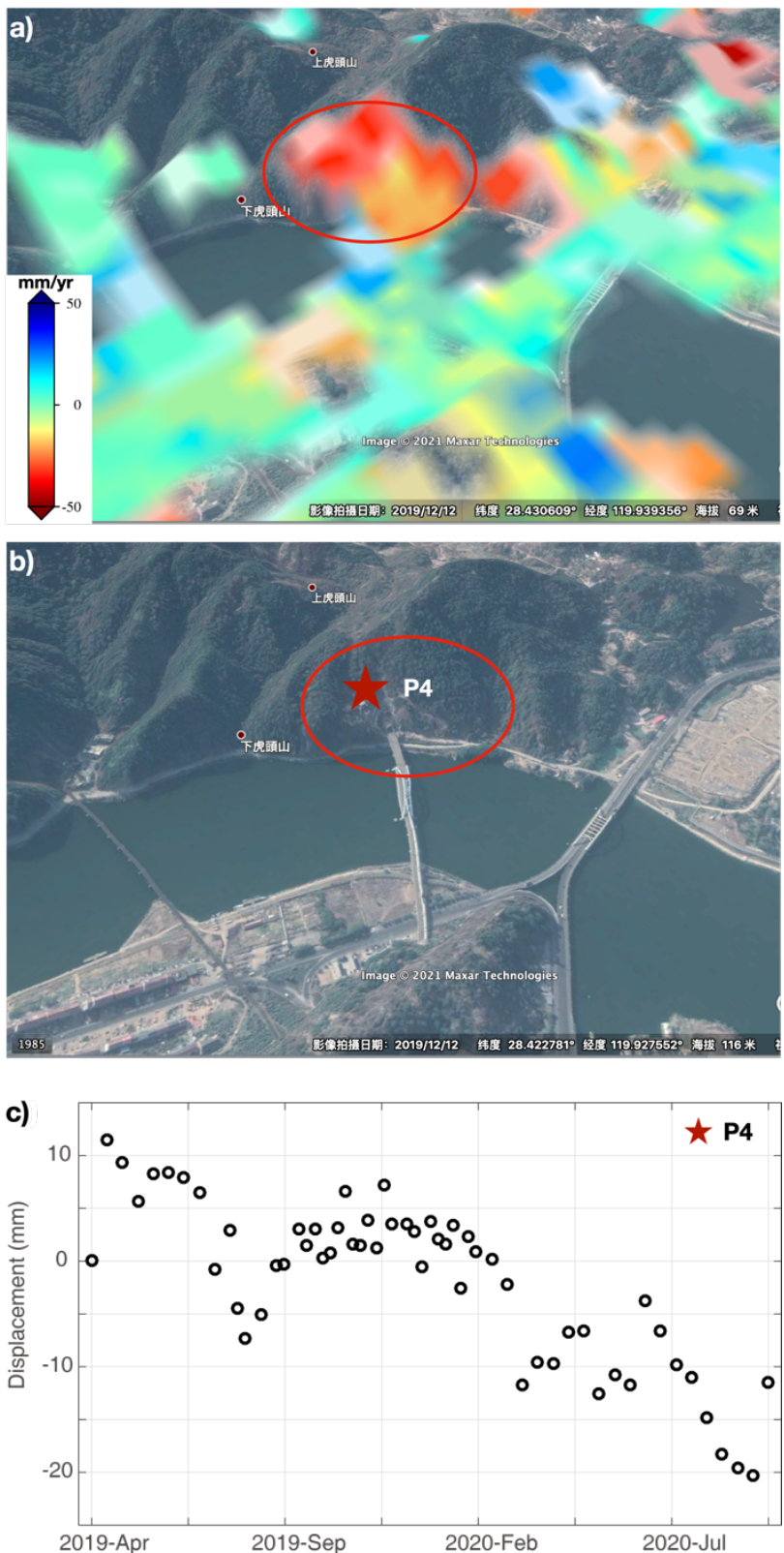

Figure 9. (a) Subsidence velocities of a mountain crossing tunnel. (b) is the corresponding Google Earth ${ }^{\mathrm{TM}}$ image of (a). (c)

Time-series displacement of $\mathrm{P} 4$ in the tunnel entrance.

In addition to the ground subsidence monitoring in urban areas, small deformation of high-voltage towers could also be detected in mountainous areas as shown in Fig. 10. The deformation points of a sets of high-voltage towers formed regular tracks in the subsidence velocity map, which is of great significance to ensure the normal operation and monitoring of high voltage lines in mountainous areas.
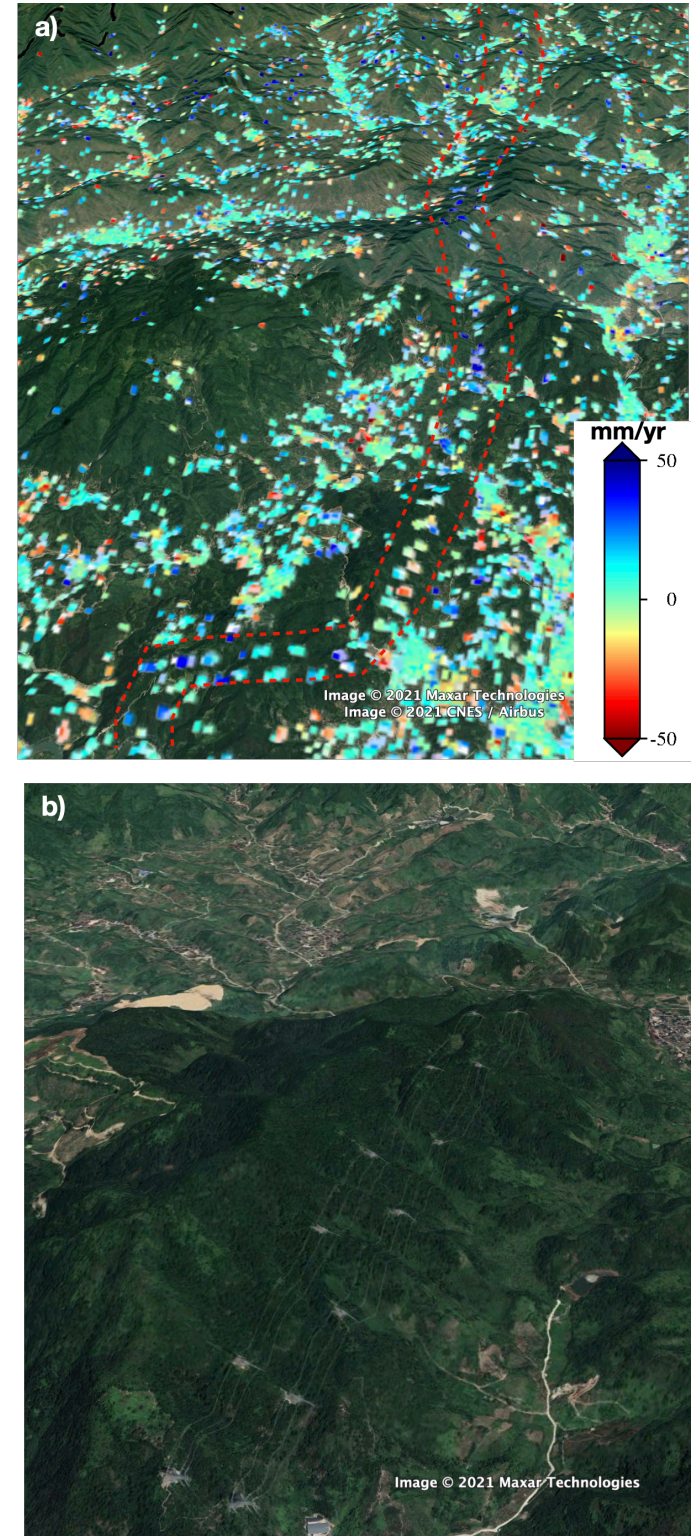

Figure 10. (a) Subsidence velocities of high-voltage towers in the mountain area. (b) is the corresponding Google Earth ${ }^{\mathrm{TM}}$ image of (a).

\section{CONCLUSIONS}

In this study, we obtained the subsidence rate map of central Lishui (China) from Sentinel-1 images acquired from 2019 to 2020. Various types of urban ground subsidence could be identified with displacement velocity of approximately 30-60 $\mathrm{mm} / \mathrm{yr}$, including the overall settlement of large construction site, the slope deformation of construction excavation, significant settlement of refuse landfill and mountain crossing tunnel, and small deformation of high-voltage towers in mountainous areas. Hence, this study indicates that InSAR is an effective tool in monitoring large-scale ground subsidence with dense measurement points in urban regions.

In the future, the upcoming LT-1 mission of China and NASA/ISRO SAR mission as well as the ESA's Copernicus program would greatly promote the continuous radar mapping of the Earth surface with shorter revisit cycles, higher monitoring accuracies and larger synchronous coverages. 


\section{ACKNOWLEDGEMENTS}

This work was supported by Chang'an University (Xi'an, China) through the National Key Research \& Development Program of China (2020YFC1512002), and also supported by "Science and Technology Project of State Grid Corporation of China" (No. 5700-201919244A-0-0-00).

The Sentinel-1 datasets are copyrighted by ESA.

\section{REFERENCES}

Berardino, P., Fornaro, G., Lanari, R., Sansosti, E., 2002. A new algorithm for surface deformation monitoring based on small baseline differential SAR interferograms. IEEE Transactions on geoscience and remote sensing, 40(11), 2375-2383.

Bürgmann, R., Rosen, P. A., Fielding, E. J., 2000. Synthetic aperture radar interferometry to measure Earth's surface topography and its deformation. Annual review of earth and planetary sciences, 28(1), 169-209.

Dong, J., Zhang, L., Tang, M., Liao, M., Xu, Q., Gong, J., Ao, M., 2018. Mapping landslide surface displacements with time series SAR interferometry by combining persistent and distributed scatterers: A case study of Jiaju landslide in Danba, China. Remote Sensing of Environment, 205, 180-198.

Ferretti, A., Fumagalli, A., Novali, F., Prati, C., Rocca, F., Rucci, A., 2011. A new algorithm for processing interferometric data-stacks: SqueeSAR. IEEE Transactions on geoscience and remote sensing, 49(9), 3460-3470.

Ferretti, A., Prati, C., Rocca, F., 2001. Permanent scatterers in SAR interferometry. IEEE Transactions on geoscience and remote sensing, 39(1), 8-20.

Hinkel, K., Doolittle, J., Bockheim, J., Nelson, F., Paetzold, R., Kimble, J., Travis, R., 2001. Detection of subsurface permafrost features with ground - penetrating radar, Barrow, Alaska. Permafrost and Periglacial Processes, 12(2), 179-190.

Gee, D., Sowter, A., Grebby, S., de Lange, G., Athab, A., Marsh, S., 2019. National geohazards mapping in Europe: Interferometric analysis of the Netherlands. Engineering geology, 256, 1-22.

Mora, O., Mallorqui, J. J., Broquetas, A., 2003. Linear and nonlinear terrain deformation maps from a reduced set of interferometric SAR images. IEEE Transactions on geoscience and remote sensing, 41(10), 2243-2253.

Shi, X., Wu, J., Ye, S., Zhang, Y., Xue, Y., Wei, Z., Li, Q., Yu, J., 2008. Regional land subsidence simulation in Su-xi-Chang area and Shanghai City, China. Engineering geology, 100(1-2), $27-42$.

Werner, C., Wegmuller, U., Strozzi, T., Wiesmann, A. (2003). Interferometric point target analysis for deformation mapping. Paper presented at the IGARSS 2003. 2003 IEEE International Geoscience and Remote Sensing Symposium Proceedings (IEEE Cat. No. 03CH37477).

Wu, J., Hu, F., 2016. Monitoring ground subsidence along the Shanghai Maglev zone using TerraSAR-X images. IEEE Geoscience and Remote Sensing Letters, 14(1), 117-121.
Wu, Q., Zhang, T., Liu, Y., 2010. Permafrost temperatures and thickness on the Qinghai-Tibet Plateau. Global and Planetary Change, 72(1-2), 32-38.

Zhang, L., Lu, Z., Ding, X., Jung, H.-s., Feng, G., Lee, C.-W., 2012. Mapping ground surface deformation using temporarily coherent point SAR interferometry: Application to Los Angeles Basin. Remote Sensing of Environment, 117, 429-439.

Zhou, C., Gong, H., Zhang, Y., Duan, G., 2016. The influence of building load to land subsidence in Beijing plain based on PS-InSAR and GIS. J. Geo-inf. Sci, 18(11), 1551-1562.

Zorigt, M., Kwadijk, J., Van Beek, E., Kenner, S., 2016. Estimating thawing depths and mean annual ground temperatures in the Khuvsgul region of Mongolia. Environmental Earth Sciences, 75(10), 897. 